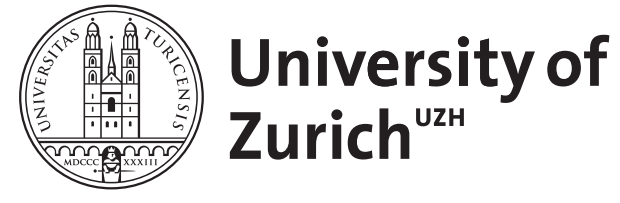

Zurich Open Repository and Archive

University of Zurich

University Library

Strickhofstrasse 39

CH-8057 Zurich

www.zora.uzh.ch

Year: 2013

\title{
In reply
}

Wuethrich, Patrick Y ; Kessler, Thomas M ; Curatolo, Michele ; Burkhard, Fiona C

DOI: https://doi.org/10.1097/ALN.0b013e3182977002

Posted at the Zurich Open Repository and Archive, University of Zurich

ZORA URL: https://doi.org/10.5167/uzh-86520

Journal Article

Published Version

Originally published at:

Wuethrich, Patrick Y; Kessler, Thomas M; Curatolo, Michele; Burkhard, Fiona C (2013). In reply. Anesthesiology, 119(1):238-239.

DOI: https://doi.org/10.1097/ALN.0b013e3182977002 
4. Zaouter C, Kaneva P, Carli F: Less urinary tract infection by earlier removal of bladder catheter in surgical patients receiving thoracic epidural analgesia. Reg Anesth Pain Med 2009; 34:542-8

\section{(Accepted for publication April 11, 2013.)}

\section{In Reply:}

We would like to thank Drs. Maxwell and Liu for their interest in our investigation and their comments. In their letter, they voiced concerns about the methodology and interpretation of our results. ${ }^{1}$

First point of criticism was our choice of words, as we used the words enhance or more pronounced in a context where the difference was not statistically significant. We were not trying to imply a statistical significance; the nonsignificant $P$ value is stated. The difference in detrusor activity actually was statistically significant during thoracic epidural analgesia (TEA) preoperatively.

The second point of criticism was the choice of postvoid residual (PVR) as primary endpoint because the measurement of PVR is variable at different times and can reflect other factors such as rate of diuresis or psychological inhibition. The urodynamic studies performed here were standardized and in accordance with the International Continence Society recommendations. Urodynamic studies for mechanistic assessment of bladder function are the most reliable method for evaluation of bladder function to date, considering them as the definitive standard investigation. ${ }^{2}$ The PVR is measured immediately after voiding per catheter, and the "endogenic" urine production is actually identifiable based on the volume filled, the volume voided, and the PVR. In this setting, the role of diuresis on PVR's can be assumed to be negligible. Because the studies were always performed in the same setting, the potential role of "psychological inhibition" on bladder function also seems questionable and purely speculative.

The Olmsted County study clearly demonstrates that most men in all age groups empty their bladder with less than $12 \mathrm{ml}$ of residual urine. ${ }^{3}$ The International Consultation on benign prostatic hyperplasia defined a range of $50-100 \mathrm{ml}$ as the lower threshold to define abnormal PVR. ${ }^{4}$ Hence, PVR changes are an acknowledged sign of impaired voiding function. The change in PVR of more than $230 \mathrm{ml}$ used here, based on precedent observations, ${ }^{5}$ can be considered a sign of a relevant change in voiding function. The other comment, concerning a previous study in patients undergoing thoracic surgery, ${ }^{6}$ further underlines the relevance of the increased PVR as a sign of impaired voiding function observed in this study. It is notable that the patients in the previous study cited by Drs. Maxwell and Liu were of younger age, another factor influencing bladder function.

We agree with Drs. Maxwell and Liu that our study was underpowered to assess the significance of the rate of urinary tract infection, but this was not the focus of our study. Concerning the decreased bladder compliance (in this case statistically significant, but of questionable clinical relevance, as it does not fulfill the criteria of a low-compliant bladder), we state in our discussion that the "ongoing drainage of the bladder" could be a confounding factor as stated by Maxwell and Liu in their letter. However, whether such a short-term drainage truly impacts compliance is debatable.

As to the ambiguity in how the primary endpoint was reported, we refer to figure 1 . During TEA, all residuals were assessed during urodynamic evaluation using a catheter (postoperative day 2) and after removal by ultrasound, where the median PVR was 0 and $2.5 \mathrm{ml}$ (return to normal), respectively. In this context, noninvasive ultrasound measurement of PVR is as accurate as measurement by catheterization. ${ }^{7}$ Concerning patients with urinary retention, we refer to the results section. Overall 12 patients were in retention during TEA postoperatively (four in the bupivacaine group and eight in the bupivacaine/fentanyl group, without reaching statistical significance).

As stated in our conclusion, we did not conclude that the urinary catheter must be left in place; on the contrary and in agreement with Drs. Maxwell and Liu, we recommend either an indwelling catheter or "a proper assessment and monitoring of PVR." In the context of 12 patients $(30 \%)$ in acute urinary retention, we underline the fact that acute bladder overdistension is an important complication, which can lead to irreversible damage to the detrusor with long-term bladder dysfunction (myogenic bladder damage). ${ }^{8}$

One strength of our study is that none of the patients needed rescue systemic opioids for postoperative analgesia, thereby excluding the potential systemic influence of opioids on bladder function. We do not see why this should compromise the external validity of the results. TEA should indeed allow for a sufficient analgesia without the need for supplemental systemic opioids.

In summary, the goal of the study was to determine the role of the drug mixture in TEA on voiding function. We observed a change in voiding function resulting in an increased PVR with a trend toward a stronger effect if fentanyl was added. This is in line with observations on systemic opioid use. ${ }^{9}$

Patrick Y. Wuethrich, M.D., D.E.A.A., * Thomas M. Kessler, M.D., Michele Curatolo, M.D., Ph.D., Fiona C. Burkhard, M.D. *University Hospital Bern, Berne, Switzerland. patrick.wuethrich@insel.ch

\section{References}

1. Wuethrich PY, Metzger T, Mordasini L, Kessler TM, Curatolo $\mathrm{M}$, Burkhard FC: Influence of epidural mixture and surgery on bladder function after open renal surgery: A randomized clinical trial. AneSTHESIOLOGY 2013; 118:70-7

2. Schäfer W, Abrams $P$, Liao L, Mattiasson A, Pesce $F$, Spangberg A, Sterling AM, Zinner NR, van Kerrebroeck P; International Continence Society: Good urodynamic practices: Uroflowmetry, filling cystometry, and pressure-flow studies. Neurourol Urodyn 2002; 21:261-74 
3. Kolman C, Girman CJ, Jacobsen SJ, Lieber MM: Distribution of post-void residual urine volume in randomly selected men. J Urol 1999; 161:122-7

4. Panicker JN, Fowler CJ: The bare essentials: Uro-neurology. Pract Neurol 2010; 10:178-85

5. Wuethrich PY, Kessler TM, Panicker JN, Curatolo M, Burkhard FC: Detrusor activity is impaired during thoracic epidural analgesia after open renal surgery. Anesthesiology 2010; 112:1345-9

6. Chia YY, Wei RJ, Chang HC, Liu K: Optimal duration of urinary catheterization after thoracotomy in patients under postoperative patient-controlled epidural analgesia. Acta Anaesthesiol Taiwan 2009; 47:173-9
7. Medical Advisory Secretariat: Portable bladder ultrasound: An evidence-based analysis. Ont Health Technol Assess Ser 2006; 6:1-51

8. Madersbacher H, Cardozo L, Chapple C, Abrams P, ToozsHobson P, Young JS, Wyndaele JJ, De Wachter S, Campeau L, Gajewski JB: What are the causes and consequences of bladder overdistension? ICI-RS 2011. Neurourol Urodyn 2012; 31:317-21

9. Panicker JN, Game X, Khan S, Kessler TM, Gonzales G, Elneil S, Fowler CJ: The possible role of opiates in women with chronic urinary retention: Observations from a prospective clinical study. J Urol 2012; 188:480-4

(Accepted for publication April 11, 2013.) 